\title{
DIALEKTIKA COSPLAY, ESTETIKA, DAN KEBUDAYAAN DI INDONESIA
}

\author{
Deni Setiawan \\ Timbul Haryono \\ M. Agus Burhan *)
}

\begin{abstract}
ABSTRACK
Culture and the type of clothing cosplay, sustainably develop in some parts of the world, such as in the United States, Japan, Australia, Paris, London, Italy, and not least in Indonesia. As well as the animation concept inherent in Japanese culture, cosplay clothing bervisual be, of course, has its advantages and disadvantages, as well as shifting ideas when diadobsi by a particular country. It is inevitable, characteristics and character animation as a reference cosplay clothing manufacture, changing its form, concept, and material when applied in Indonesia. Cosplay Indonesia, for example, how this all adopt dialihmaterialkan business, as well as experienced changes in search of ideas to show all the elements of Indonesia 's. Making the next cosplay outfit based on stories, fairy tales, novels, legends, and comics in Indonesia. This arrangement is not without reason and without creativity, but more depth can be discussed as a form of acculturation between the ideas of Japanese and Indonesian culture, which is packed into a cosplay outfit. On the other arts areas, the concept of cosplay is often shown as a costume show. For example, in the theater, revue, or a play-play in an event that featured performances on the stage space. The concept of clothing with a special place and time, is a simple concept of cosplay. Visualize concepts ideas or writings on clothing image and makeup, which is transformed into three- dimensional shapes. Cosplay should be viewed as a discourse of culture and art, by adopting textual ideas, concepts imagination image, into forms such a unique and beautiful.
\end{abstract}

Key words : cosplay, cosplayer, aesthetic principles, various forms, and ideology.

\section{ABSTRAK}

Budaya dan jenis pakaian cosplay, secara berkesinambungan berkembang di beberapa belahan dunia, seperti di Amerika Serikat, Jepang, Australia, Paris, London, Italia, dan tidak terkecuali di Indonesia. Seperti halnya dalam konsep animasi yang melekat pada budaya Jepang, bervisual menjadi pakaian cosplay, tentunya memiliki kelebihan dan kekurangan, serta mengalami pergeseran ide-ide manakala diadobsi oleh negara tertentu. Tidak dapat dipungkiri, ciri khas dan karakter animasi sebagai rujukan pembuatan pakaian cosplay, mengalami

* Deni Setiawan, Dosen Fakultas IImu Pendidikan, Universitas Negeri Semarang, E-Mail: denijusmani@gmail.com. Timbul Haryono, Dosen Program Studi Pengkajian Seni Pertunjukan dan Seni Rupa, Sekolah Pascasarjana, Universitas Gadjah Mada.

M. Agus Burhan, Kritikus Seni Rupa, Dosen Fakultas Seni Rupa, dan Pembantu Rektor I Institut Seni Indonesia Yogyakarta. 
perubahan bentuk, konsep, dan material ketika diaplikasikan di Indonesia. Cosplay Indonesia misalnya, bagaimana usaha adobsi ini dialihmaterialkan, serta mengalami perubahanperubahan dalam pencarian ide-ide dengan menampilkan unsur-unsur ke-Indonesia-an. Pembuatan pakaian cosplay pada selanjutnya berdasarkan pada cerita, dongeng, novel, legenda, dan komik-komik di Indonesia. Penggubahan ini bukan tanpa alasan dan tanpa kreativitas, tetapi lebih mendalam dapat dibahas sebagai bentuk akulturasi antara ide-ide kebudayaan Jepang dan Indonesia, yang dikemas menjadi pakaian cosplay. Pada wilayah kesenian lain, konsep cosplay juga sering ditampilkan sebagai sebuah kostum pertunjukan. Misalnya pada pertunjukan teater, pertunjukan tari-tarian, atau sebuah lakon-lakon yang ditampilkan dalam sebuah acara pertunjukan diatas ruang pentas. Konsep pakaian dengan tempat dan waktu khusus, adalah konsep sederhana dari cosplay. Konsep-konsep yang memvisualkan ide-ide gambar ataupun tulisan tentang pakaian dan tata rias, yang ditransformasikan menjadi bentuk tiga dimensi. Cosplay seharusnya dipandang sebagai wacana kebudayaan dan kesenian, dengan mengadobsi ide-ide tekstual, konsep imajinasi gambar, menjadi bentuk-bentuk rupa yang unik dan indah.

Kata-kata kunci: cosplay, cosplayer, prinsip estetika, ragam bentuk, dan ideologi.

\section{PENDAHULUAN}

Membicarakan cosplay, tentu tidak akan terlepas dari persoalan kerajinan tangan, dunia rancang pakaian, industri aksesori, serta terkait erat dengan hobi. Artikel ini, tentunya berfokus pada persoalan kajian budaya terhadap karyakarya kriya, sehingga menjadi penting sebagai pembatas persoalan yang menjadi pembahasan. Sebagai wujud karya kriya, cosplay memiliki sekelumit persoalan yang bersentuhan langsung dengan masalah sosial, budaya, industri pakaian, dan industri kreatif lainnya. Cosplay, merupakan kependekan dari costume dan play, berkembang dengan konsep yang mengadobsi kebudayaan animasi di Jepang, yang diwujudkan menjadi karya pakaian. Selain film animasi, adobsi ini bersumber dari komik, di Jepang dikenal dengan manga. Cosplay secara spesifik menunjukkan kecintaan beberapa orang remaja yang terdiri atas komunitas- komunitas, terhadap film animasi dan karakter manga. Cosplay di Jepang, seringkali dimunculkan pada festivalfestival pakaian, karnaval, dan tentunya mendapat dukungan penuh dari industri pakaian, sebagai wujud percepatan ekonomi kreatif yang memberikan ruangruang khusus bagi desainer dan pencipta pakaian.

Dalam anneahira.com Cosplay pertama kali muncul di Amerika Serikat pada 1960-an, yang dikenalkan oleh para penggemar cerita dan film fiksi ilmiah di Amerika Serikat, melalui konvensi fiksi ilmiah. Dalam konvensi ini para peserta memiliki kebiasaan untuk mengenakan kostum, seperti yang dipakai oleh tokohtokoh film fiksi ilmiah dalam film, seperti Film Star Trek. Didalam kebudayaan Amerika Serikat mengenal bentuk-bentuk pesta topeng (masquerade), termasuk dalam perayaan Haloween dan Paskah. Budaya ini kemudian mulai berkembang ke 
Jepang pada dekade 1970-an. Di Jepang, budaya cosplay muncul pertama kali pada peragaan busana di Ashinoko, Prefektur Kanagawa pada tahun 1978, dalam bentuk pesta topeng konvensi fiksi ilmiah Nihon SF Taikai ke-17. Dalam acara tersebut Mari Kotani, seorang kritikus fiksi ilmiah hadir dengan memakai kostum tokoh dalam cerita A Fighting Man of Mars karya Edgar Rice Burroughs. Selain itu, terdapat Direktur perusahaan animasi Gainax, Yasuhiro Takeda tampil dengan kostum unik mengambil tema tokoh Star Wars. Mereka berdua adalah tokoh yang memiliki peran penting wabah cosplay di Jepang. Kontes cosplay kemudian menjadi acara rutin sejak Nihon SF Taikai ke-19 pada 1980. Semenjak tahun 1980, cosplay semakin marak diselenggarakan di Jepang. Majalah Fanroad edisi perdana bulan Agustus 1980, memuat liputan khusus tentang munculnya kelompok anak muda yang menamakan diri "Tominoko-zoku". Komunitas ini merupakan sekelompok anak muda yang gemar ber-cosplay di kawasan Harajuku, dengan menggunakan kostum Gundam.

Cosplay, sebetulnya secara langsung menunjuk budaya berpakaian dengan rujukan animasi (film dan game) dan komik, setiap negara memiliki karakter dan ciri khas sebagai penanda kebudayaan. Cosplay di Indonesia, diberitakan mulai dikenal sekitar tahun 1998,' walaupun tidak seramai pada akhir-akhir ini. Menurut anneahira.com Ketika Universitas Indonesia mengadakan Gelar Jepang dengan mengadakan kegiatan cosplay pada awal tahun 2000-an, peminatnya masih sedikit. Sesudah kegiatan yang berlangsung di Universitas Indonesia itu berakhir, beberapa komunitas remaja di Bandung mulai memperkenalkan gaya Harajuku. Berawal dari acara inilah, hampir setiap bulan selalu ada pameran pakaian cosplay di kota-kota besar di Indonesia, seperti: Jakarta, Bandung dan Yogyakarta. Pada awalnya cosplayer Indonesia masih sangat Jepang sentris, artinya kostum-kostum yang dipakai merujuk pada tokoh-tokoh komik dari Jepang. Memang ada beberapa cosplayer dengan ide gagasan pada tipe Eropa, tetapi diambil dari manga/manwa, dan bukan dari komik di luar Asia.

Peluang industri pakaian akan terbuka luas, manakala kebutuhan untuk eksistensi dan hobi terhadap cosplay ini semakin berkembang. Tidak saja para desainer dan perancang pakaian yang terkena keuntungan, industri pasar, industri garmen, dan industri aksesori turut serta menikmati kehadiran cosplay sebagai lahan ekonomi baru. Pada sisi lain, invansi kebudayaan cosplay ini semakin mengukuhkan keberperanan fungsi-fungsi sekunder pada pakaian, yang tidak terbatas pada jenis-jenis kasual, melainkan terdapat nilai-nilai baru pakaian. Pada cosplay, terdapat banyak sekali pengalaman berkesenian yang dapat ditemukan mulai dari fashion design, keterampilan membuat pola dan menjahit, kemampuan craftmanship, pembelajaran make up, aktivitas akting dan koreografi, seni fotografi dan foto editing, termasuk audio dan video editing. Karena bagaimanapun harus disadari, cosplay ini adalah seni berpakaian dan seni berakting, keduanya harus ada secara bersamaan, sebagai bagian peniruan karakter pakaian dan kepribadian tokoh yang diidolakan (dijadikan percontohan). Tentunya, ini 
bukanlah hobi yang murah dan gratis, diperlukan kemauan dan kerja keras cermat untuk menghasilkan pakaian cosplay dengan kualitas baik, termasuk penggunaan aksesorinya.

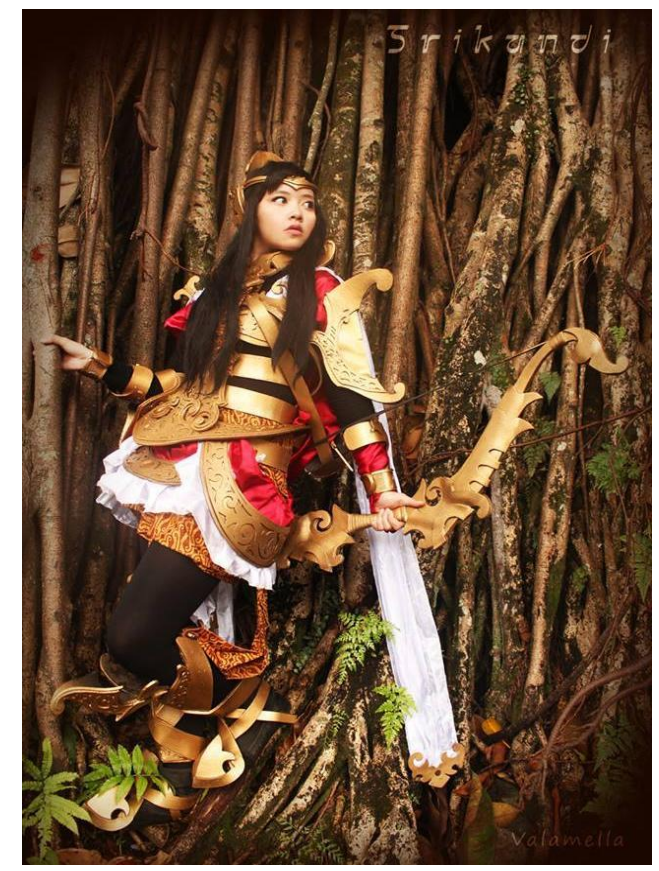

Gambar 1. Cosplay Srikandi

Oleh : Aurin Aiza, Photographer: Valamella

Kota: Bandung, Jawa Barat, Sumber: Komunitas Cosplay Indonesia

Perubahan dan akulturasi yang terjadi pada cosplay, memungkinkan gaya dan hobi berpakaian dengan rujukan animasi dan manga ini berkembang sesuai dengan kondisi sosial, budaya, dan kemampuan berkreativitas dari pencipta pakaian itu sendiri. Pada akhirnya, hadir pula konsep-konsep dengan nuansa lokalitas, baik dalam penggunaan rujukan, maupun dengan material yang digunakan dalam pembuatan pakaian. Munculnya cosplay dengan nama-nama lokal seperti pakaian Si Buta dari Gua Hantu, Wiro Sableng, Dewi Ular, Gatotkaca, versi Saint Wayang, beberapa bersumber dari cerita komik dan pendekar dunia persilatan di Indonesia, menunjukkan terjadi dialektika kebudayaan didalamnya. Cosplay tidak selalu harus dilihat dari persoalan estetika, dapat pula diteliti secara mendalam melalui konteks kajian budaya, konsep industri, konsep kesejarahan, melihat hal semiotika, walaupun tidak akan lepas dari apa yang disebut sebagai prinsip-prinsip kebentukan visual. Lokalitas cosplay sebetulnya muncul dalam rangka melihat peluang-peluang hasil kebudayaan (komik, film, animasi, ataupun cerita heroisme) di Indonesia diwilayah lokal, nasional, dan internasional. Cosplay berdasarkan atas kesenangan dan hobi, dibuatkan komunitas, dan dieksekusi oleh industri, dan akhirnya dapat menjadi suatu hal fenomenal.

\section{PEMBAHASAN}

\section{A. Konsep-konsep Pakaian Cosplay}

Ide cosplay bersumber pada animasi (film dan game), ataupun dari manga. Cosplay ini menjadi populer dikarenakan ketertarikan terhadap tokohtokoh idola, yang dikagumi, dan ingin ditiru, serta diwujudkan penampilannya dalam dunia nyata. Kekaguman ini dapat mengacu banyak hal, seperti: kesaktian, kehebatan, kecantikan, karakter dan kepribadian, ataupun pada keunikan dan estetisnya pakaian beserta atribut yang digunakan. Selain memang terdapat alasan personal, rasa ingin diakui, diperhatikan, solidaritas terhadap komunitas, serta rasa penasaran untuk tampil semirip mungkin dengan tokoh yang dikagumi. Perkembangan cosplay tentunya tidak terlepas dari kekaguman atas budaya animasi yang hampir dimiliki disetiap negara. Manga Jepang misalnya, dengan judul shining gum dan shojo bin, 
diterbitkan dan populer di Amerika Serikat. Terdapat film Spirited Away karya Hayao Miyazaki yang memenangkan Oscar di Amerika Serikat pada tahun 2003 sebagai film animasi terbaik. Manga seringkali menggambarkan kebudayaan Jepang, dimulai dengan sejarah kepahlawanan sampai cerita remaja yang memiliki penggemar tidak hanya bagi warga Jepang saja.

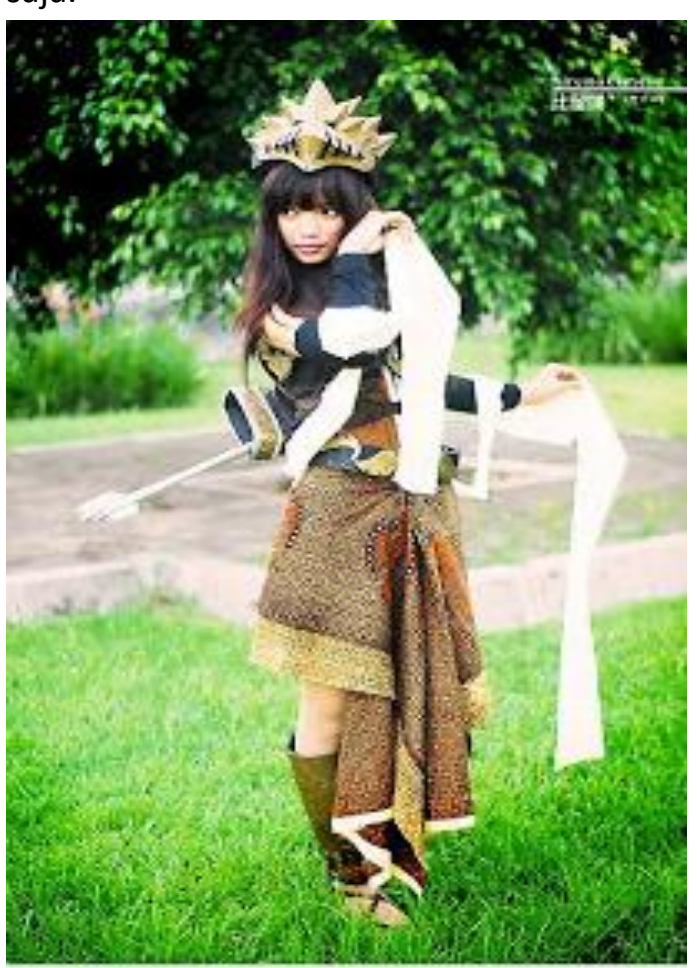

Gambar 2. Cosplay Srikandi

Tema: Wayang Indonesia, Pewayangan Jawa Photographer: Hilma Khuriroy

Sumber: http://chou-inyucosplay.blogspot.com/

Pada sisi lain, di Jepang misalnya,

dari segi perekonomian cosplay memberikan sumbangan sebesar 40 Miliar Yen, sehingga perannya perlu diperhitungkan. Ide pembuatan cosplay tidak selalu mengacu pada manga saja, melainkan juga meniru pada acara live action, film-film non Jepang. Keseriusan negara Jepang dalam hal cosplay dapat terlihat dengan dibuatnya konsep kota Akihabara pada tahun 2010, sebagai kota yang diperuntukkan bagi mereka penggemar dan ingin bercosplay dijalanan. Kehadiran tokoh publik dengan pakaian cosplay semakin memperkuat penyebaran dan perkembangannya pada masyarakat luas. Beberapa artis Korea yang populer di Indonesia-pun seringkali menampilkan kostum-kostum unik dengan gaya cosplay, sehingga kehadiran cosplay di ranah kebudayaan semakin populer.

Dalam anneahira.com disebutkan ada beberapa kategori dalam cosplay, diantaranya: (1) cosplay anime/manga, yang berasal dari anime maupun manga; (2) Cosplay manhwa atau komik dari Amerika termasuk di dalamnya; (3) cosplay game, tipe ini diambil dari karakter di dalam Game; (4) Selain itu ada cosplay Tokusatsu diambil dari karakter dalam film Tokusatsu; cosplay Gothic, menggunakan karakter bernuansa gelap atau gaya Gotik, biasanya menggabungkan Lolita; (5) cosplay Original, tidak mengacu pada anime, tokusatsu, dan lainnya; (6) didalamnya juga terdapat Harajuku Style.

$$
\text { Cosplay (コスプレ kosupure) }
$$

adalah istilah bahasa Inggris versi Jepang (wasei-eigo) yang berasal dari gabungan kata costume (kostum) dan play (bermain). Cosplay berarti hobi memakai pakaian beserta aksesori dan rias wajah, seperti yang biasa digunakan oleh tokoh-tokoh dalam anime, manga, manhwa, dongeng, permainan video, penyanyi dan musisi idola, dan film kartun. Menurut Fukiko Mitamura, cosplay adalah merubah diri menjadi peran yang dibutuhkan atau status yang diinginkan, terlepas dari apakah orang tersebut memang berprofesi sebagai peran 
yang sedang dimainkan atau tidak, memiliki kemampuan yang dituntut harus dimiliki oleh peran yang dimainkan atau tidak. Dengan kata lain, seseorang dapat menjadi bagian dari suatu profesi atau peran hanya dengan memakai kostum yang menandai peran tersebut, sehingga seseorang akan merasa menjadi seperti orang yang diperankannya, sehingga mau tidak mau merasa berkewajiban untuk memiliki kemampuan sesuai dengan tuntutan profesi atau peran yang dimainkan, sesuai dengan kostum. ${ }^{\text {ii }}$

Menurut pengamatan seorang peneliti kebudayaan Jepang, Aji Yudistira, secara garis besar, cosplay terbagi atas dua jenis berdasarkan tujuannya, yaitu: cosplay yang berusaha menjadi karakter tertentu dan yang berusaha untuk diperlihatkan. Cosplay karakter dikenal dengan nama kyarakosu (キャラコス) dari kata kyarakutaa kosupure. Dalam cosplay jenis ini biasanya sang cosplayer atau yang biasa disebut Layer (レイヤー), akan ber-cosplay berdasarkan tokoh atau karakter tertentu di dalam anime, manga, game. Akan tetapi tidak hanya terbatas meniru, juga membuat originalitas sendiri berdasarkan karakter atau tokoh anime, manga, dan game. Dengan berbasis kepada kostum dan aksesoris suatu tokoh, layer mencoba memodifikasi kostum yang diciptakannya sendiri, atau bahkan membuat kostum ciptaannya sendiri. Cosplay karakter juga tidak hanya meniru kostum karakter saja, tetapi juga termasuk didalamnya mempersonifikasikan suatu benda yang disukai, cosplay ini dikenal dengan istilah Gijinka (擬人化). Contohnya para pengemar kereta, mereka ber-cosplay dengan mencoba membuat kereta yang disukai, dengan kostum dan aksesoris yang menjadi ciri khas dari kereta, seakan-akan kereta tersebut hidup dan memakai baju (kostum). iii

Pada jayapoken.blogspot.com, untuk cosplay yang diperlihatkan, lebih memusatkan perhatiannya untuk memang diperlihatkan. Dikenal dengan istilah yunikosu (ユニコス) yang merupakan singkatan dari yunifoomu kosupure (그二 フォームコスプレ) atau Uniform Cosplay (Cosplay Seragam). Cosplay ini menggunakan seragam-seragam tertentu, yang sudah dikenal secara umum oleh masyarakat. Biasanya seragam-seragam ini berhubungan dengan profesi, contohnya cosplay dengan baju pelayan, serafuku (baju seragam sailor yang biasa dipakai pelajar Sekolah Menengah Pertama dan Sekolah Menengah Atas di Jepang). Cosplay untuk diperlihatkan biasanya erat hubungannya dengan dunia usaha, yang memang menjual penampilan sebagai layanan kepada para pelanggan.

Tren kostum dan pakaian cosplay yang berkembang di Jepang, setiap tahun mengalami perubahan, tema kostum biasanya sesuai dengan tren pada tahun tertentu. Pada 2011 misalnya, cosplay banya didominasi kostum-kostum animasi, seperti tokoh Naruto dan tokoh game online Ragnarok asal Korea. Pada tahun 2012, tren kostum akan berubah lebih ke arah Indonesia, tetapi tidak sepenuhnya meninggalkan unsur-unsur kostum khas Jepang. Kostum tokoh wayang menjadi populer bagi komunitas cosplayer pada tahun 2012. Gaya baru yang lebih dengan karakter tokoh pewayangan Indonesia terinspirasi komik Indonesia berjudul Garudayana. Komik Indonesia ini 
mengangkat tokoh wayang dan dengan gambar bergaya Jepang.

\section{B. Aktivitas Cosplay di Indonesia}

Aktivitas cosplay di Indonesia sebagian besar dimulai melalui komunitas dan kelompok kecil, yang memiliki kesamaan hobi. Beberapa biasanya diselenggarakan pada komunitaskomunitas kampus yang memiliki Jurusan Sastra Jepang, atau jurusan-jursan yang terkait dengan negara Jepang. Di Indonesia, komunitas cosplayer ini seringkali menyelenggarakan kegiatan cosplay dalam skala nasional, sebutlah iFest Cosplay Contest dan Maid Lolita Contest yang diselenggarakan pada 5 Mei 2012 di Gambir Expo, Jakarta. Selain itu ada Cosplay Charity For Indonesia di Paris Van Java \& Gardenice, PVJ Bandung, pada tanggal 20-21 November 2010. Kegiatan dan lomba cosplay pada acara Grand Final Megaxus Olimpiade 2011 di Mall Taman Anggrek, tanggal 15-18 September 2011, Jakarta. Anime Festival Asia di Indonesia, Plenary Hall, Jakarta Convention Center, pada 6, 7 dan 8 September 2013. The Best Indonesian Otakus Event, Area Gambir Expo, Arena PRJ Kemayoran, Jakarta, pada tanggal 2-3 November 2013. Wilayah Yogyakarta tidak ketinggalan membuat kegiatan cosplay, seperti kegiatan Jogja Care for Japan-Let's Support and Learn from Japan yang dipusatkan di Gedung Jogja Expo Center, pada tanggal 26 Maret 2011.

Di Bali ada komunitas Dewata Cosplay yang berdiri pada 16 Oktober 2011, tidak hanya menampilkan animasi Jepang saja, tetapi juga gaya Amerika Serikat. Selain itu terdapat Japan Evoution
Community adalah sebuah komunitas anime atau japan club di kawasan Tulungagung Jawa Timur, yang terbentuk pada tanggal 11 Agustus 2007. Ko-J-Tsu (baca : kojitsu) adalah komunitas Jepang Surabaya, yaitu sebuah wadah yang dapat menampung dan menyalurkan semua inspirasi, aspirasi dan kreativitas anak-anak Surabaya yang tertarik dan menyukai segala hal terkait dengan Jepang, baik itu dari segi musikalitas, film, anime, manga, tokusatsu maupun dari kebudayaan negara Jepang. Beberapa komunitas lain, seperti: Komuitas Hourglass (Semarang-Jawa Tengah), Kuji (Kudus Japan Community, Kudus-Jawa Tengah), Shiratsuki (SemarangJawa Tengah), komunitas ALICE (Anime Lovers Independent $\mathrm{CrEw}$ ) yang memiliki cabang di Kalimantan, Jakarta, Surabaya. Komunitas Vern di Yogyakarta, terbentuk pada tanggal 28 April 2006. Di Yogyakarta juga ada komunitas lain, seperti: Komunitas Amanogawa, Hoshizora Community, Atsuki Community, Grup online yang mewadahi para cosplayer ini adalah Komunitas Cosplay Indonesia, juga Komunitas Harajuku dan Cosplay di Indonesia.

Komunitas memiliki peran penting bagi seseorang atau sekelompok orang untuk menyampaikan gagasan dan ide kepada masyarakat luas. Tidak terkecuali gagasan tentang cosplay, akan lebih mudah disampaikan kepada publik, jika disertai dengan pergerakan organisasi yang teratur, mengelompok, dan memiliki kepentingan, serta hobi yang sama. Menurut Jasmadi, sebuah komunitas akan memiliki empat ciri utama, yaitu: terdapat keanggotaan di dalamnya, bersifat saling mempengaruhi, terjadi integrasi dan pemenuhan 
antaranggota, berlangsungnya ikatan emosional antaranggota (Jasmadi, 2008:17). Apa yang terjadi dalam komunitas cosplay adalah bagaimana nilainilai pakaian dikemas menjadi sedemikian rupa, sehingga tampak menarik, menyenangkan, dan unik, untuk kemudian disajikan kembali kepada masyarakat luas. Sifat saling mempengaruhi, sebetulnya dapat dikatakan sebagai bentuk penyebaran informasi mengenai hal-hal yang terkait dalam dunia cosplay, penokohan, informasi aksesori, atau bertukar pikiran mengenai keberadaan komunitas ini di Indonesia maupun di luar negeri.

\section{Cosplay dan Prinsip Estetika Dewitt H. Parker}

Berikut ini akan dipaparkan beberapa prinsip estetika dan dialektika pada cosplay.

\section{Prinsip Kesatuan Organik}

Seorang desainer pakaian, Elsa Schiaparelli mengatakan, bahwa bukan pakaian yang beradaptasi dengan tubuh manusia, melainkan sebaliknya, tubuhlah yang beradaptasi dengan pakaian (Lars Svendsen, 2006: 77). Terjadi semacam dialog antara tubuh dan pakaian, pakaian dan konteks sosial, keduanya saling beradaptasi untuk kepentingankepentingan tertentu. Tahapan selanjutnya tentu tidak terlepas dengan persoalan identitas keduanya, identitas tubuh dan identitas pakaian. Sebuah wujud dan tema pakaian melabelkan hal baru pada tubuh, memberikan perbedaan karakter, tempat, waktu, dan persoalan ideologis antara tubuh satu dengan yang lainnya. Seperti yang digambarkan oleh ahli Sosiologi, Anthony Giddens, bahwa bagaimana tubuh menjadi sebuah benda refleksif yang identitasnya terbentuk dikarenakan oleh identitas pakaian.

Cosplay pada dimensi kultural adalah mengelompoknya hasrat-hasrat bergaya, yang terwadah dalam komunitas pecinta kebudayaan animasi (dominannya Jepang) dan manga. Pada dimensi berkesenian, ia adalah ekspansi besarbesaran ekspresi yang terwujud dalam desain dan seni bermain peran. Karena cosplay memiliki dimensi spesial, dimana seseorang melalui pakaian ini, juga "wajib" memahami karakter "pemilik" pakaian yang digunakan. Misalkan pakaian cosplay dengan tokoh Naruto, harus dipahami betul keidentikan dominan yang melekat pada Naruto, demikian pun pada tokoh idola lainnya. Pada dimensi kultural lainnya, cosplay tidak saja berimplikasi pada wilayah personal, tetapi terjadi massifikasi ideologi animasi terhadap wilayah publik. Ke-kontemporan seni dan ideologi, sepertinya melegalkan cosplay untuk berakumulasi menjadi budaya lokal. Pada akhirnya, lahirnya pakaian cosplay dengan idola tokoh Indonesia semacam $\mathrm{Si}$ Buta dari Gua Hantu dan Wiro Sableng, merupakan bukti nyata, bahwa cosplay dibesarkan dengan bersumber pada tokoh fiksi.

Eksistensi kecintaan pada cosplay, menambah daftar panjang terjadinya pembauran kebudayaan asing dan lokal. Cosplay pada tataran tertentu mampu memberikan kepuasan berpakaian, tidak saja dalam hal hasrat dan ekspresi, tetapi juga persoalan bagaimana memerankan karakter penjiwaan suatu tokoh tertentu 
secara total. Dimensi play (cos and play) yang memberikan penekanan dan betapa spesialnya karakter pakaian ini. Kekhususan dalam hal play, membatasi pakaian ini untuk direduksi dalam pakaian kasual (sehari-hari), membedakannya dari peragaan pakaian umumnya, dan tentu, keidentikan pakaian cosplay merupakan wujud identitas pakaian yang digunakan.

Ada hal yang menarik untuk diketengahkan dalam ranah berpakaian dalam konteks cosplay. Dalam wujud pakaian cosplay merupakan perkembangan nilai-nilai "tradisi" yang menjadi kultur dunia animasi, dikemas dalam persoalan mode. Pada ranah lain, terjadi distorsi makna terhadap nilai-nilai berpakaian; dimana, berpakaian menjadi alat untuk mempersatukan tujuan dalam mencapai apa yang disebut bergaya. Istilah bergaya, dalam konteks berpakaian, terpahami sebagai aplikasi luar yang digunakan untuk memanipulasi orang lain, sehingga memiliki kesan sosial yang terkonsep, terbentuk sebagai persoalan hasrat-hasrat individu.

Hasrat-hasrat berpakaian inilah yang mengarahkan seseorang individu, atau pun sekelompok orang, untuk mengkonsumsi produk-produk industri (pakaian) sebagai perpanjangan tangan kultur animasi. Sebagai sebuah kultur, domain ide cosplay merujuk pada era digital yang diterjemahkan dalam wujud visual pakaian. Pada akhirnya, kesamaan para cosplayer di beberapa daerah (bahkan negara), adalah tentang mengelompoknya hobi yang sama (cinta budaya animasi), kepopuleran tokoh, persoalan ranah bergaya, dan pengakuan identitas terhadap kelompok masyarakat.

\section{Prinsip Unsur Dominan}

Pada kehidupan sosial sehari-hari sangat akrab dengan komersialisasi, begitu banyak komoditi yang bersirkulasi, memanjakan manusia dengan hasrathasrat untuk mengkonsumsi. Di dalam kebiasaan mengkonsumsi, logikanya bukan lagi kebutuhan (needs), melainkan logika hasrat (desires). Menurut Gilles Deleuze dan Felix Guattari, hasrat tidak akan pernah habis dan terpenuhi, karena terdapat mesin hasrat, selalu terjadi reproduksi hasrat secara terus menerus (Yasraf Amir Piliang, 2003: 150). Hasrat untuk mendapatkan pengakuan sosial yang muncul pada setiap personal, merupakan wujud pencarian identitas dalam masyarakat. Identitas ini jugalah yang membedakan setiap manusia, lingkungan sosial, termasuk juga landasan berpikir untuk bergaya. Persoalan identitas adalah mutlak dan menjadi konsep utama dalam fungsi berpakaian (Svendsen, 137). Pakaian memberikan kontribusi terhadap pembentukan identitas. Identitas ini menjadi hal penting saat bertemu dengan komunitas sosial tertentu, gaya hidup setiap individual yang divisualkan melalui gaya berpakaian, mencerminkan gaya hidup komunal yang dicitrakan melalui simbol-simbol manusia tradisional dan postradisional. Dalam pemahaman Giddens, masyarakat sosial modern memiliki karakter pencitraan diri personal yang individual dan kuat, dimana rujukannya tetap bernuansa tradisional (Svendsen, 137).

$$
\text { Kesepakatan bergaya dalam }
$$

cosplay merupakan "aturan" yang disepakati komunitas penggunanya, yang disadari atau tidak, membentuk tanda- 
tanda yang berkomunikasi dalam konteks. Sekumpulan tanda yang terorganisir dinamakan sebagai kode dan aturan kesepakatan tersebut yang kemudian "dikodekan" (John Fiske, 2007: 91). Tidak ada kode pertandaan yang dapat dipisahkan dari praktek sosial penggunanya. Sifat dasar kode, yaitu: (1) memiliki dimensi paradigmatik (terdiri sejumlah unit kode) dan sintagmatik (sejumlah unit kode dapat disatukan); (2) menyampaikan makna; (3) bergantung pada kesepakatan pengguna dan latar belakang budaya yang sama. Kode dan budaya saling berinterelasi secara dinamis; (4) menunjukkan fungsi sosial; (5) dapat ditransmisikan melalui media (Fiske, 2007: 92).

Susunan tanda yang berupa kode, sangat dilandasi ideologi mendasar dari apa yang hendak dikodekan. Dalam pakaian cosplay dan apa yang dipikirkan oleh cosplayer, merupakan hal atau ide pokok dari persoalan yang dinamakan konsep berpikir dari rancangan pakaian cosplay itu sendiri. Tentu, tidak terlepas dari sumber-sumber pemikiran yang terkait dalam pembentukan pakaian cosplay. Ada sesuatu makna yang ingin disampaikan; dengan kata lain, cosplay adalah menunjuk tatanan ide personal dengan segala macam kerumitannya. Pada saat lain, cosplay berevolusi menjadi teks-teks yang saling berhubungan antara desainer, pengguna (penggaya), dan lingkungan sosial. Ada sesuatu yang disistemasikan, kesepakatan yang muncul adalah dalam konteks fungsi sosial, dalam hal ini pengakuan identitas. Pada akhirnya, kepentingan desainer cosplay dan cosplayer sangat ditentukan oleh media.
Sebetulnya, letak pokok persoalan dalam bergaya adalah bagaimana mengemas tampilan, atau berpenampilan yang mampu membedakan atau menyamakan (mengikuti mode, bermode) diri dengan lingkungannya. Cosplay merupakan persoalan penampilan, sekaligus menunjuk komunikasi nonverbal yang saling berkorelasi antara desainer, individu, dan lingkungan atau komunitas bergaya. Oleh karena itu, dalam hal berpenampilan, Argyle membagi menjadi dua, yaitu: berdasarkan aspek sukarela (rambut, pakaian, kulit, warna kulit, dan perhiasan); berdasarkan aspek yang tidak dapat dikontrol (tinggi badan, berat badan). Penampilan digunakan untuk mengirimkan pesan tentang kepribadian, status sosial, dan konformitas (Fiske, 2007: 96). Secara sukarela cosplayer (dengan segala keterbatasan dan kelebihan) menjadi agen-agen budaya berpakaian, dengan bergaya cosplay. Sukarela tidak semata-mata terbentuk atas keinginan normal, melainkan terbentuk oleh peran dan pengaruh lingkungan sosial, termasuk iklan. Di dalam iklan, tanda digunakan secara aktif dan dinamis, sehingga orang membeli produk untuk (bergaya), bukan atas kebutuhan, melainkan membeli makna-makna simbolik; konsumer diposisikan terpesona makna simbolik, daripada fungsi kegunaan pada benda yang dibelinya (Piliang, 287). Pada sisi lain, personal-personal yang menjadi komunitas pecinta cosplay, wujud dari aktualisasi diri terhadap komunitas lingkungan sosial.

Menurut pandangan Rogers, aktualisasi diri adalah proses menjadi diri sendiri dan mengembangkan sifat-sifat dan potensi potensi psikologis yang unik. 
Aktualisasi diri akan dibantu atau dihalangi oleh pengalaman belajar khususnya dalam masa kanak kanak. Aktualisasi diri akan berubah sejalan dengan perkembangan hidup seseorang. Ketika mencapai usia tertentu (adolensi) seseorang akan mengalami pergeseran aktualisasi diri dari fisiologis ke psikologis. Aktualisasi diri ini disebabkan untuk memenuhi kebutuhan, diantaranya: kebutuhan fisiologis, kebutuhan rasa aman, kebutuhan cinta, dan kebutuhan untuk mendapat penghargaan (Suane Schultz, 1997). Abraham Maslow, menyimpulkan bahwa seseorang melakukan aktualisasi diri, apabila kebutuhan fisiologis (kebutuhan makan dan minum), rasa aman, kebutuhan sosial, dan kebutuhan akan harga diri belum terpenuhi dengan baik. Kebutuhan fisiologis, rasa aman, dan kebutuhan cinta muncul sebagai perkembangan jiwa dan raga seseorang, berkembang secara alamiah atau pun dikondisikan dalam kondisi tertentu (dalam Suane Schultz).

Beberapa tanda pada cosplay mengindikasikan pada kebutuhan rasa aman, cinta, diterima, dan mencari penghargaan pada konteks lingkungan tertentu. Cosplay menjadi media ungkapan untuk berkomunikasi dengan lingkungan sosial, sehingga didapatkan prestige dan kepuasan hati manakala tujuan tercapai dan tersampaikan dengan baik. Selain itu, cosplay menjadi media untuk saling berkomunikasi bagi cosplayer dan bertukar karakter, ide, dan saling meminjamkan hasrat untuk saling beraktualisasi diri.

\section{Prinsip Keseimbangan}

Jika melihat konsep pikir Nanang Rizali, maka menurut jenisnya mode (fashion) dibagi menjadi empat macam, yaitu: Special Fashion, High Fashion, Medium Fashion, dan Standard Fashion. Dalam perkembangannya empat fashion terbagi lagi menjadi delapan aliran yang menjadi ciri khas tersendiri, yaitu: Aliran Classic dan New Classic, Aliran Houte Couture dan Trendy, Aliran New Waves dan Cycle, serta aliran Fads dan Ready to Wear (Jurnal Seni Rupa dan Desain, Volume 1, 1, Agustus 2000). Berdasarkan pada konsep tersebut, pakaian cosplay menjadi bagian dari special fashion. Special fashion dapat diterjemahkan sebagai pakaian yang penggunaannya hanya dalam konteks waktu, tempat, dan situasi tertentu saja. Selain, memang dapat ditarik benang merah dengan dress code, yang membatasi konteks tempat dan waktu saat berpakaian.

Prinsip mendasar pada penciptaan pakaian adalah bagaimana cara membuat pakaian lama (agar tampak kuno), segera digantikan dengan pakaian baru (Svendsen, 28). Eksistensi pakaian saling berinteraksi antara masa lalu dengan saat ini, pada beberapa rentang zaman, mengalami perulangan bentuk. Bentuk masa kini tidak dapat dikatakan sebagai bentuk "saat ini", melainkan refleksi wajah pakaian masa lalu. Roland Barthes mengklaim, bahwa pakaian adalah suatu wacana perbincangan masa lalu (Svendsen, 31). Bentuk pakaian selalu berotasi dalam putaran yang tetap, dimana perputaran tersebut hanya persoalan waktu dan tempat, saat pakaian digantikan dengan bentuk baru. Pakaian mengalami dekontekstualitas dan rekontekstualitas dari pembentukan tradisi yang lain, sehingga hampir tidak ada bentuk pakaian yang sifatnya original. 
Hal yang berlaku pada cosplay, dalam perulangan bentuk dan perbicangan masa lalu, ditampilkan melalui transformasi pakaian animasi digital ke pakaian pakai. Istilah masa lalu merujuk pada ide-ide mendasar dalam khazanah desain pakaian yang digunakan dalam gaya cosplay. Wacana dimensi waktu adalah persoalan yang dalam upayanya untuk membedakan beberapa persoalan, seperti: klasifikasi, tema, tempat, material, komunitas, dan fenomena kultural dalam cosplay. Pelembagaan dan klasifikasi cosplay dilakukan untuk memberikan gambaran anatomi setiap bagiannya. Ini juga membatasi ranah cosplay dan bukan cosplay, sekaligus penanda perbedaan kemasan, baik hal gaya, atau pun penjiwaan terhadap suatu pakaian yang digunakan. Pada dimensi umum, cosplay merupakan sebuah produk dengan tujuan untuk dipamerkan pada masyarakat umum. Konsep teori yang melekat pada cosplay, sebetulnya masih sejalan dengan apa yang dicetuskan oleh Desmond Morris mengenai fungsi pokok pakaian, yaitu: pakaian untuk kenyamanan, pakaian untuk kesopanan, dan pakaian sebagai benda pameran (Desmond Morris, 2002: 320). Pakaian cosplay dan segala aksesori yang melekat, masuk pada bagian pakaian sebagai benda pameran.

Pada sumber buku yang sama, fungsi kenyamanan merupakan hal pokok dan paling penting, bukan persoalan sosial, dan masuk wilayah pribadi (Morris, 320). Sejak awal, pakaian diciptakan untuk melindungi tubuh dari berbagai macam masalah, termasuk menjaga dari penyakit. Pada cosplay, pakaian mengalami dekonstruksi pemaknaan dan tujuan penggunaan, yang berbeda dengan pakaian umum. Jika menurut Richard Corson, cosplay ini masuk pada kategori pakaian fantasi, yang hanya dapat diterima oleh kelompok, disajikan dalam konteks waktu, tempat, dan wacana tertentu saja (Richard Corson, 1981). Pakaian cosplay melalui dimensi personal, merupakan ekspresi jiwa melalui media pakaian, dengan tujuan utama untuk mencari nilai popularitas dan pencitraan. Pencitraan di wacana iklan, membentuk masyarakat konsumer menjadi kelompok-kelompok gaya hidup, yang pola kehidupannya diatur berdasarkan tema, citra, dan makna simbolik tertentu (Yasraf Amir Piliang, 2003: 290). Setiap kelompok gaya hidup menciptakan ruang sosial, yang didalamnya gaya hidup dikonstruksi.

Persoalan lain dari cosplay adalah pakaian sebagai bentuk ekspresi individualistik. Gagasan Malcolm Barnard menyoroti persoalan pakaian sebagai penanda untuk membedakan dirinya sendiri sebagai individu dan menyatakan bentuk keunikannya (Malcolm Barnard, 2009: 85). Pakaian cosplay digunakan sebagai media untuk mengekspresikan keunikan individu atau komunitas terhadap kecintaan budaya animasi dan manga. Sebagai media ekspresi, cosplay tidak dapat lepas dari tema-tema pakaian yang ditampilkan atau diciptakan, tetap terikat pada konsekuensi dan aturan dalam menciptakan pakaian cosplay. Dress code atau tema pakaian memberikan batasan dan kemudahan bagi desainer dan cosplayer dalam menciptakan pakaian dan tokoh tertentu. Aturan tema adalah mutlak ada pada pakaian cosplay.

Pencitraan dan ekspresi individualistik merupakan persoalan 
mendiskursuskan keseimbangan gagasan konsep tentang pakaian cosplay dan makna yang menyertainya. Kode sosial pakaian cosplay merefleksikan kebudayaan populer dan serbuan dimensi digital pada kehidupan kesenian tradisional. Ada dua unsur saling terkait dalam praktek industri mode yang merupakan kunci untuk godaan konsumen: merk dan fantasi. Merk adalah alat untuk penciptaan fantasi. Sebagai catatan McRobbie dalam contoh di atas, merk melampaui visual untuk mewakili fantastis gambar atau pengalaman suatu produk (Linda Leung, ed., 2008: 27). Pakaian cosplay mencitrakan tentang merk atau label, yang memang diciptakan untuk "menggiring" imajinasi konsumen untuk menyukai dunia pakaian dan animasi.

\section{PENUTUP}

Pada akhirnya, pakaian cosplay (sama halnya dengan jenis pakaian lainnya) merupakan perwujudan dinamis dalam perkembangan teknologi mencipta dan budaya pakaian. Dinamis dalam hal ide-ide, tema, dan mengalami perkembangan penerimaan dan pencitraan pada dimensi sosiokultural, serta membentuk pola pikir baru terhadap cara dan alasan berpakaian. Dunia fantasi dan pakaian yang tercipta bersumber dari ide tersebut, memiliki beberapa isi dan komunikasi untuk masyarakat sosial. Misalnya pada pakaian cosplay, ia berkomunikasi terhadap lingkungannya melalui media pakaian, dengan tema-tema fiksi, digital, dan pencampuran beragam ideologi didalamnya. Pencampuran ideologi ini membentuk pola pikir baru, yang menghasilkan kesimpulan adanya suatu faham ideologi yang berbeda dengan rujukannya. Setidaknya, cosplay merupakan ide-ide kebudayaan Jepang, saat berevolusi pada tatanan lokal, budaya tersebut saling mempengaruhi dengan kultur Indonesia, menghasilkan perwajahan baru pakaian cosplay.

Tidak saja berdampak signifikan pada lingkungan masyarakat sosial pendukung gaya cosplay, lebih luas memiliki pengaruh terhadap perkembangan perekonomian dan industri pakaian di Indonesia. Gaya dan pencitraan adalah pertalian erat yang tidak dapat dipisahkan dari kultur sosial kehidupan manusia diseluruh belahan dunia, sehingga mampu dijadikan sebagai mesin untuk memuaskan hasrat-hasrat. Cosplay adalah penjara gaya hidup, dan pakaian adalah medianya.

\section{DAFTAR PUSTAKA}

Barnard, Malcolm. Fashion sebagai Komunikasi: Cara Mengkomunikasikan Identitas Sosial, Seksual, Kelas, dan Gender. Yogyakarta: Penerbit Jalasutra, 2009.

Chuang, Ejen. Cosplay in America. USA: Optik Nerve, 2010.

Corson, Richard. Stage Makeup. Englewood Cliffs, New Jersey: Prentice-Hall, Inc., 1981.

Craik, Jennifer. The Face of Fashion: Cultural Studies In Fashion, New York: Routledge, 1993.

Fortunati, Leopoldina, et al. Mediating the human body : technology, communication, and fashion. New Jersey: Lawrence Erlbaum Associates, Inc., Publishers. 
Jasmadi, Membangun Komunitas Online Secara Praktis dan Gratis. Jakarta: Elex Media Komputindo, 2008.

Lehmann, Ulrich. Tigersprung: fashion in modernity, USA: Massachusetts Institute of Technology, 2000.

Leung, Linda, ed. Digital Experience Design: Ideas, Industries, Interaction. Chicago: Intellect Bristol, 2008.

Morris, Desmond. Peoplewatching: The Desmond Morris Guide to Body Language. London: Vintage Books, 2002.

Piliang, Yasraf Amir. Hipersemiotika: Tafsir Cultural Studies Atas Matinya Makna. Yogyakarta: Penerbit Jalasutra, 2003.

Rizali, Nanang. "Kecenderungan Pasar dan Perkembangan Mode Sebagai Alternatif Pendekatan dalam Perancangan Tekstil Cetak", dalam Jurnal Seni Rupa dan Desain, Volume 1, 1, Agustus 2000 (Bandung: Pusat Penelitian dan Pengembangan Masyarakat (P3M) Sekolah Tinggi Seni Rupa dan Desain Indonesia).

Schultz, Suane. Psikologi Pertumbuhan: Model-model Kepribadian Sehat, Terjemahan Yustinus. Yogyakarta: Kanisius, 1997.

Svendsen, Lars. Fashion: a philosophy. London: Reaktion Books Ltd., 2006.

Troy, Nancy J. Couture culture : a study in modern art and fashion, USA: Massachusetts Institute of Technology, 2003.

Vinken, Barbara. Fashion Zeitgeist: Trends and Cycles in the Fashion System, New York: Berg Oxford International Publishers Ltd., 2005.

\section{Sumber Internet}

http://www.anneahira.com/cosplay.htm http://gallerycosplayindonesia.wordpress.c om/

http://international.okezone.com/read/20 13/09/23/562/870517/cosplaybukan-sekadar-pakai-kostum http://japanlunatic.do.am/index/manga_d an_cosplay/0-80

http://jurnalotaku.com/2013/05/29/faktaindustri-cosplay-di-jepang/

http://komunikasi.us/index.php/matakuliah/kmm/17-tmb-umb/6271teknologi-dan-budaya-cosplay-diindonesia

http://siskailkom12.wordpress.com/2013/ 02/20/komunitas-cosplay/

http://www.femina.co.id/isu.wanita/topik. hangat/komunitas.cosplay.indones ia/005/007/51

http://www.indoanime.net/forum/topic/9 963-jepang-komunitas-jepang-diindonesia/

http://www.radarjogja.co.id/component/c ontent/article/19-utama/23126cosplay-bukan-sekadar-gaya-anakmuda.html

CATATAN:

i Wawancara dengan Pinku-san sebagai seorang cosplayer generasi awal di Indonesia, lihat di: http://gallerycosplayindonesia.wordpress.com/, diakses pada 28 September 2013, pukul 17.09 WIB.

ii Disarikan dari tulisan bebas pada: http://jayapoken.blogspot.com/2011/10/apa-sihcosplayitu.html?showComment=1326291927802\#c7041199 296828157341, diakses pada 29 September 2013, pukul 13.25 WIB.

iii Acara Bincang-bincang Mengenai Cosplay di Japan Foundation Jakarta, tanggal 24 Oktober 2011. 